\title{
Effects of an in situ instructional design based postpartum hemorrhage simulation training on patient outcomes
}

Citation for published version (APA):

de Melo, B. C. P., Van der Vleuten, C. P. M., Muijtjens, A. M. M., Rodrigues Falbo, A., Katz, L., \& Van Merrienboer, J. J. G. (2021). Effects of an in situ instructional design based postpartum hemorrhage simulation training on patient outcomes: an uncontrolled before-and-after study. Journal of Maternal-Fetal \& Neonatal Medicine, 34(2), 245-252. https://doi.org/10.1080/14767058.2019.1606195

Document status and date:

Published: 17/01/2021

DOI:

10.1080/14767058.2019.1606195

Document Version:

Publisher's PDF, also known as Version of record

\section{Document license:}

Taverne

\section{Please check the document version of this publication:}

- A submitted manuscript is the version of the article upon submission and before peer-review. There can be important differences between the submitted version and the official published version of record.

People interested in the research are advised to contact the author for the final version of the publication, or visit the DOI to the publisher's website.

- The final author version and the galley proof are versions of the publication after peer review.

- The final published version features the final layout of the paper including the volume, issue and page numbers.

Link to publication

\footnotetext{
General rights rights.

- You may freely distribute the URL identifying the publication in the public portal. please follow below link for the End User Agreement:

www.umlib.nl/taverne-license

Take down policy

If you believe that this document breaches copyright please contact us at:

repository@maastrichtuniversity.nl

providing details and we will investigate your claim.
}

Copyright and moral rights for the publications made accessible in the public portal are retained by the authors and/or other copyright owners and it is a condition of accessing publications that users recognise and abide by the legal requirements associated with these

- Users may download and print one copy of any publication from the public portal for the purpose of private study or research.

- You may not further distribute the material or use it for any profit-making activity or commercial gain

If the publication is distributed under the terms of Article $25 \mathrm{fa}$ of the Dutch Copyright Act, indicated by the "Taverne" license above, 


\section{Effects of an in situ instructional design based postpartum hemorrhage simulation training on patient outcomes: an uncontrolled before-and- after study}

\section{Brena Carvalho Pinto de Melo, Cees P. M. Van der Vleuten, Arno M. M.} Muijtjens, Ana Rodrigues Falbo, Leila Katz \& Jeroen J. G. Van Merriënboer

To cite this article: Brena Carvalho Pinto de Melo, Cees P. M. Van der Vleuten, Arno M. M. Muijtjens, Ana Rodrigues Falbo, Leila Katz \& Jeroen J. G. Van Merriënboer (2021) Effects of an in situ instructional design based postpartum hemorrhage simulation training on patient outcomes: an uncontrolled before-and-after study, The Journal of Maternal-Fetal \& Neonatal Medicine, 34:2, 245-252, DOI: $10.1080 / 14767058.2019 .1606195$

To link to this article: https://doi.org/10.1080/14767058.2019.1606195

央 Published online: 25 Apr 2019.

Џll Article views: 229

View Crossmark data $־$
Submit your article to this journal $\pi$

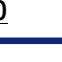




\title{
Effects of an in situ instructional design based postpartum hemorrhage simulation training on patient outcomes: an uncontrolled before-and- after study
}

\author{
Brena Carvalho Pinto de Melo ${ }^{\mathrm{a}, \mathrm{b}, \mathrm{c}}\left(\mathbb{D}\right.$, Cees P. M. Van der Vleuten ${ }^{\mathrm{b}}$ (D) Arno M. M. Muijtjens ${ }^{\mathrm{b}}$ (D), \\ Ana Rodrigues Falbo ${ }^{c, d, e}$ (D), Leila Katz ${ }^{a, e}$ (ID) and Jeroen J. G. Van Merriënboer ${ }^{b}$ (D) \\ ${ }^{a}$ Centro de Atenção, à Mulher, Instituto de Medicina Integral Prof Fernando Figueira (IMIP), Recife, Brazil; ${ }^{b}$ Faculty of Health, \\ Medicine and Life Sciences, School of Health Professions Education, Maastricht University, Maastricht, The Netherlands; ${ }^{\mathrm{C}}$ Medical \\ Course, Faculdade Pernambucana de Saúde (FPS), Recife, Brazil; ${ }^{\mathrm{d}}$ Faculty Development Coordination, Faculdade Pernambucana de

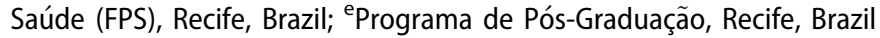

\begin{abstract}
Objective: To compare postpartum hemorrhage (PPH) patient outcomes before and after an in situ instructional design based PPH simulation attended by obstetrics and gynecology (OBGYN) residents.

Methods: This uncontrolled before-and-after study was conducted in Recife, Brazil including all 1388 women delivering from June to August 2012 and all 1357 delivering from June to August 2013. The 36 OBGYN residents were divided into13 teams of two or three participants and were trained through ID based PPH simulation training with the following eight steps: (1) prior knowledge activation, (2) video demonstration, (3) dual-coding PPH protocol discussion-an image association during the training, (4) training scenario \# 1, (5) debriefing, (6) training scenario \# 2 with immediate feedback, (7) training scenario \# 3, and (8) debriefing with self-assessment. The training scenarios had an increasing level of complexity. The main goal of the training was the adequate management of PPH and situational awareness improvement-the ability to anticipate, recognize, and intercept unfolding error chains. The primary patient outcomes rates used for the before and after comparison were therapeutic uterotonics use within $24 \mathrm{~h}$ of birth and blood transfusion. Secondary outcomes were therapeutic oxytocin mean dosage IU within $24 \mathrm{~h}$ of birth, postpartum $\mathrm{Hb}<6 \mathrm{~g} / \mathrm{dL}$, among others. Chi-square test was used for categorical variables comparison and independent $t$-test for continuous variables.

Results: PPH rates were 100 (7.2\% of 2012 deliveries) and 80 cases (5.9\% of 2013 deliveries), respectively. Comparison of primary post- and pre-simulation outcomes revealed no significant differences. However, in the comparison for therapeutic oxytocin mean dosage IU within $24 \mathrm{~h}$ of birth, there was an increase found after the simulation $(15.98 \pm 7.4$ versus $25.1 \pm 12.3 ; p<.001)$. For all other outcome measures, there were no statistical differences.

Conclusions: In situ ID based PPH simulation leads to an increase in the mean dosage of oxytocin after training, in selected cases. This may indicate better situational awareness when managing women with $\mathrm{PPH}$.
\end{abstract}

ARTICLE HISTORY

Received 22 January 2019

Revised 18 March 2019

Accepted 8 April 2019

\section{KEYWORDS}

Instruction; instructional design guidelines; patient outcome; postpartum hemorrhage; simulation

\section{Introduction}

Postpartum hemorrhage (PPH) is widely adopted as a training content for obstetrics emergencies simulation since most of its related deaths are attributed to delays in recognition and management [1,2]. PPH simulation training should aim, therefore, to optimally manage postpartum bleeding in women by improving birth attendants' situational awareness (ability to perceive, comprehend and project a situation) [3] and complex learning skills (integration of knowledge, skills, and attitude) [4]. Strong evidence of the impact of simulation on patient outcomes is, however, still lacking $[5,6]$.

Assessing the impact of simulation on patient outcomes is considered the ultimate level in assessing training effectiveness. According to the Kirkpatrick training evaluation model, there are four levels of measured effects: learner's reaction, learning, transfer of learning (applying what was learned in the workplace), and results (patient outcomes) [7]. Search for evidence regarding simulation effectiveness has recently broadened to include the impact on transfer 
of learning and patient outcomes (Levels 3 \&4), after initially focusing on learners' reaction and learning (Levels 1 \&2) [8-11]. The current inconsistency of findings on simulation patient outcome studies, however, may be attributed to wide variation in reporting of training design and outcomes [11,12].

Simulation training ultimately aims to improve patient outcomes and should prioritize instructional effectiveness with the use of instructional design guidelines [13]. ID guidelines derive from sound learning theories and propose the use of instructional features such as authenticity, variability, increasing complexity, and feedback for optimal complex learning and training effectiveness $[4,14,15]$. Systematic reviews of the use of such features in simulations have corroborated their effectiveness and demonstrated that these are still not widely used $[16,17]$.

Proper PPH management requires early recognition and prompt bleeding control (i.e. adequate situational awareness) and minimizes complications such as blood transfusions, hysterectomy, near-miss maternal mortality, or maternal death $[2,3,18]$. It requires coordination of constitutively different skills (e.g. communication, drug management) as other obstetric emergencies [2]. These characteristics reinforce PPH value as subject for simulation. Of the wide variety of reported PPH outcomes, those presented most common are uterotonics administration and/or blood transfusion rates $[11,18]$.

In this current study, we aim to compare outcomes of women presenting with PPH at a tertiary teaching hospital maternity before and after an in situ ID based PPH simulation training offered to obstetrics and gynecology (OBGYN) residents.

\section{Materials and methods}

This uncontrolled before-and-after study compared PPH patient outcome data for one sample before in situ ID based PPH simulation training (June to August 2012) and another after (June to August 2013). Data were collected from all women whose births were assisted at the Instituto de Medicina Integral Prof Fernando Figueira (IMIP), a tertiary teaching hospital in Recife, Northeast of Brazil with a 6000/year delivery rate maternity.

All women whose labours were assisted at IMIP during data collection were considered eligible for inclusion. Women were excluded from the study when, after assistance, their pregnancies were reclassified as $<20$ weeks (late abortion). Figure 1 presents a flow chart of participants' data collection.
The ID based PPH simulation training was offered to all 45 of the hospital's OBGYN residents, during their off-duty hours, in situ (at actual hospital facilities). Thirty-six residents, from all 3 years of the residency program, attended the training, an $80 \%$ attendance rate. During each of the two half-day-long in situ simulation sessions scheduled for the first two weekends of June 2013, two groups of two or three OBGYN residents' teams were trained.

The in situ ID-based simulation was designed for a postgraduate audience to address adequate PPH management and its complex learning demands. It contained multiple steps and the three authentic training scenarios were presented in a simple-to-complex sequence (from uncomplicated retained placenta to unresponsive hypotonic uterus leading to hemodynamic instability). Two debriefings sessions provided the team with video recordings and a self-assessment stage. Scenarios included a standardized patient, a standardized nurse, and a part-task pelvis simulator (EVA Simulador Pós-Parto; ProDelphus, Olinda, Brazil). The simulation overall learning objective was to achieve complex learning regarding promptly and adequately managing postpartum bleeding according to the PPH guideline presented, covering tasks involving skills, knowledge, and attitudes (SKA). The multiple tasks were classified into subscales: communication, teamwork, vital signs, venous access, laboratory evaluation, and drug, mechanical, and surgical management (the latter solely by verbal indication). Further design details may be consulted elsewhere $[19,20]$.

The main outcome measures selected were therapeutic uterotonic use within-24h-of-birth and blood transfusion. Secondary outcome measures included therapeutic uterotonic dosages and rates per drug (oxytocin, misoprostol and ergotamine), within and beyond $24 \mathrm{~h}$-of-birth, and other severity-related PPH outcomes such as: hemoglobin levels $<6 \mathrm{~g} / \mathrm{dL}$, BLynch suture, uterine artery embolization, hysterectomy, renal insufficiency (as registered on patient records), obstetric ICU admission, mechanical ventilation, hospital length of stay after birth, near-miss maternal mortality, and maternal death. These outcomes were selected through a Delphi panel of OBGYN experts which rated PPH most relevant management outcomes as described in related systematic reviews [21]. The list of outcomes measures in increasing complexity order (least to most complex) is provided in Appendix 1.

Data regarding women's age, parity, gestational age, mode of delivery, newborn birth weight, and prophylactic oxytocin administration were collected 


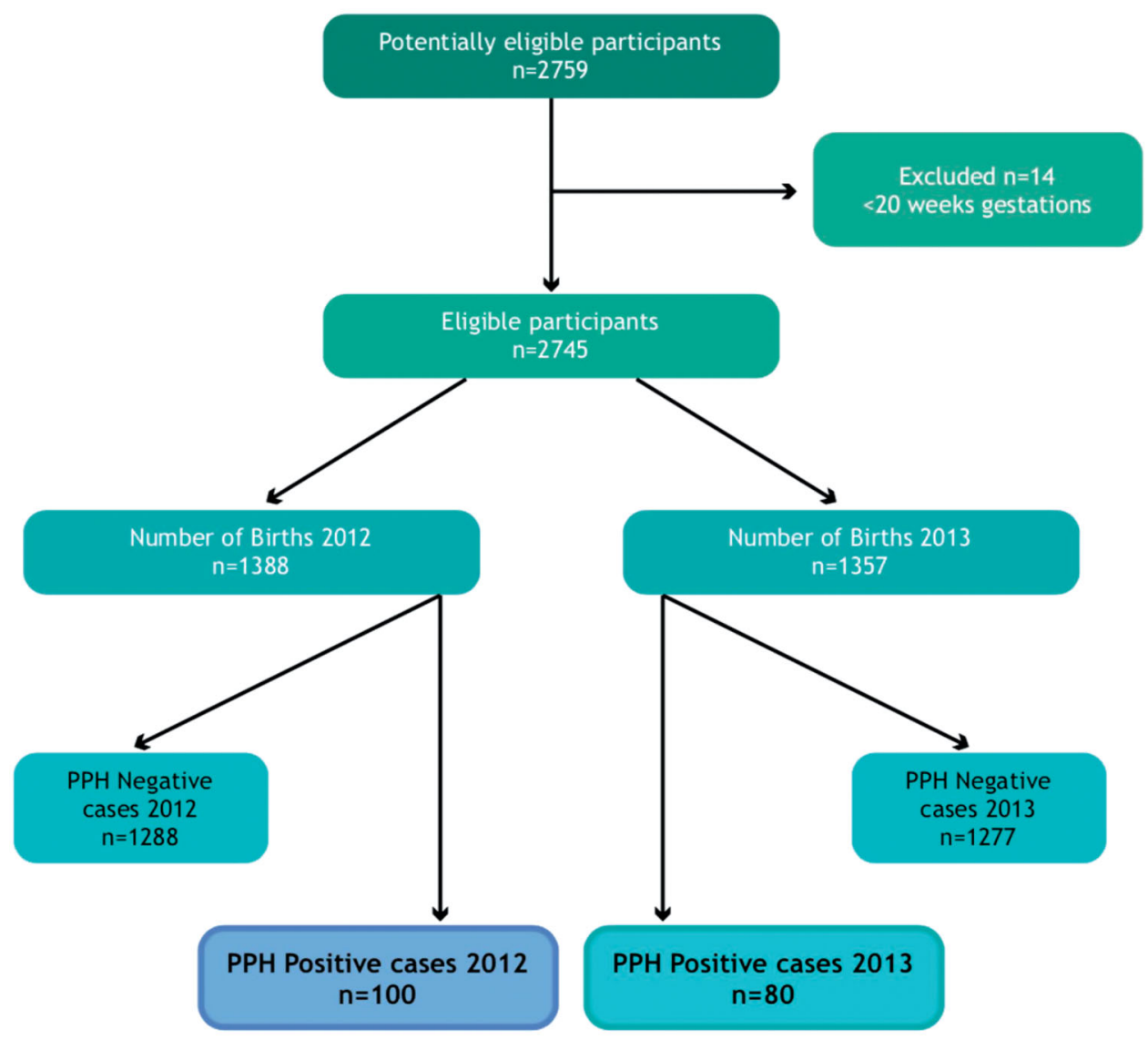

Figure 1. Data collection flow chart.

from all women included in the study. PPH outcomes measures were collected for those women identified as PPH cases, using a specific chart. All skilled birth attendants were trained for data collection and made aware when data collection was under way by daily rounds.

During data collection, women's patient records were provided with additional flow chart which was inserted immediately before the maternity hospital's regular labour and delivery flow chart. All women admitted either in labour or for expectant management were monitored for delivery. The team of professional birth attendants during each of the maternity hospital's two 12-h daily shifts is composed by four OBGYN medical residents, three OBGYN medical consultants, and one obstetric nurse. All deliveries are assisted by at least one of these professionals, with the participation of at least one medical OBGYN resident. These are the first responders to the low-risk births assisted by nurses. A PPH case triggers a call. High-risk births are initially assisted by the medical OBGYN residents. Medical consultants are available to supervise residents' deliveries assistance and/or cesarean sections.
Upon delivery, the birth attendant registered at the additional flow chart whether the women presented $\mathrm{PPH}$, after collecting their data collection consent, while also producing routine paper work, typically 1 hour after delivery. The hospital adopted criteria for identifying PPH is based on traditional definitioncumulative blood loss of greater than or equal to $1000 \mathrm{~mL}$ or blood loss accompanied by signs or symptoms of hypovolemia-as assessed by the birth attendant. Women were monitored throughout their hospital stay for continuous blood loss. In the event of PPH occurring later than 1 hour after birth, i.e. after registration of birth records, maternity personnel were urged, during daily rounds, to register the incident on the PPH data collection flow chart. Patients' records of all women included in the study were reviewed upon hospital discharge for data collection inconsistencies.

Women were also monitored if admitted to the obstetric intensive care unit. This unit is a referral center for severe obstetrics patients from throughout the region and case severity vary widely, from single need for vigilance cases to more complex cases, with need for advanced life support. The prevalence of 
Table 1. Demographic and clinical characteristics of women presenting with postpartum hemorrhage (PPH) at a teaching hospital in June, July and August 2012/2013 before and after an in situ instructional design based postpartum hemorrhage simulation training.

\begin{tabular}{|c|c|c|c|c|c|}
\hline & \multicolumn{2}{|c|}{2012} & \multicolumn{2}{|c|}{2013} & \multirow{2}{*}{$\begin{array}{c}\text { Total } \\
p \text { Value }\end{array}$} \\
\hline & 1388 deliveries & Valid cases & 1357 deliveries & Valid cases & \\
\hline PPH intrapartum (up to $1 \mathrm{~h}$ after birth) $N$ (\%) & $63(63 \%)$ & 100 & $45(56.3 \%)$ & 79 & $.412^{c}$ \\
\hline PPH postpartum ( $>1 \mathrm{~h}$ after birth) $N(\%)$ & $46(46 \%)$ & 100 & $37(46.3 \%)$ & 80 & $.973^{\mathrm{C}}$ \\
\hline Age Mean $( \pm S D)$ & $25.16 \pm 6.4$ & 100 & $25.92 \pm 7.6$ & 80 & $.467^{\mathrm{a}}$ \\
\hline Gesta Median (IQR) & $1,5(1-3)$ & 98 & $2(1-3)$ & 79 & $.72^{\mathrm{b}}$ \\
\hline Para Median (IQR) & $0(0-1)$ & 98 & $1(0-2)$ & 80 & $.42^{\mathrm{b}}$ \\
\hline Prophylactic oxytocin N (\%) & $82(82 \%)$ & 100 & $64(80 \%)$ & 80 & $.733^{c}$ \\
\hline Cesarean $N(\%)$ & $37(37 \%)$ & 99 & $32(40 \%)$ & 80 & $.720^{c}$ \\
\hline Neonatal Birth Weight Mean $( \pm S D)$ & $2488.89 \pm 1123.55$ & 99 & $2642.75 \pm 1022.97$ & 80 & $.345^{\mathrm{a}}$ \\
\hline Admission in Labour $N(\%)$ & $45(45 \%)$ & 98 & $35(43.8 \%)$ & 78 & $.890^{c}$ \\
\hline Induced Labour N (\%) & $40(40 \%)$ & 98 & $25(31.3 \%)$ & 79 & $.208^{\mathrm{C}}$ \\
\hline Preterm on admission $N(\%)$ & $45(45 \%)$ & 100 & $32(41 \%)$ & 78 & $.595^{\mathrm{C}}$ \\
\hline
\end{tabular}

Obs1: a: $t$-test; b: Mann-Whitney $U$ test; c: Pearson Chi-Square tests.

Obs2: Each variable was calculated based on the number of valid cases (missing cases excluded).

preeclampsia in the locality is high and women needing magnesium sulfate are admitted for vigilance.

Women's delivery assistance during data collection was not modified for any reason, with a naturalistic observation of their management for the full length of their hospital stay. Data were collected in the same months of 2012 and 2013 to avoid potential seasonality bias and no change was therefore expected regarding $\mathrm{PPH}$ rates and the focus was on analyzing outcome measures. This current study was approved by the IMIP's ethics committee on 17 March 2012 under the number CAE:0034.0.099.000-11.

Data were analyzed using SPSS version 23 (IBM, Armonk, NY, USA). Patient data and outcomes frequency measures were aggregated per year of occurrence, and between-year differences (i.e. post- versus pre-simulation outcomes) were also investigated. The chi-square test was used for all categorical variables comparisons and Fisher's exact test used when necessary. An independent $t$-test was conducted to compare the means of continuous variables and the Mann-Whitney test was applied for discrete variables.

\section{Results}

During data collection, 2759 women were assisted for delivery at IMIP. Fourteen were excluded for gestational age $<20$ weeks (late abortions). Of all 2745 women who delivered during data collection period, 1388 were in 2012 and 1357 in 2013, with PPH rates of 100 cases (7.2\% of deliveries) and 80 cases (5.9\%), respectively. Analysis of demographic and clinical data revealed no statistically significant differences between women presenting with PPH before and after simulation (Table 1).

Differences found between the main pre- and postin situ ID based PPH simulation outcomes of therapeutic uterotonic rates within-24 h-of-birth of 67/ $100(67 \%)$ and $47 / 80(58.8 \%)(p=.254)$ and blood transfusion rates of 29/100 (29\%) and 24/79 (30\%) (p $=.768)$ respectively were not statistically significant.

As for secondary outcomes comparison, a statistically significant difference was found for per drug therapeutic uterotonic use within-24h-of-birth, with an increase in the mean dose of therapeutic oxytocin in IUs $(15.98 \pm 7.4$ versus $25.1 \pm 12.3 ; p<.001)$ after simulation (Table 2).

The increase in misoprostol use rate $(14 / 100(14 \%)$ versus $19 / 80(23.8 \%) ; p=.093)$ and the mean dose in $\mu \mathrm{g}$ within $24 \mathrm{~h}(592 \pm 261.54$ versus $736 \pm 164 ; p=$ $.084)$ and the decrease in the number of near-miss cases $(8 / 100(8 \%)$ versus $3 / 78(3.8 \%) ; p=.352)$ and $\mathrm{Hb}$ $<6 \mathrm{~g} / \mathrm{dL}(23 / 99$ (23\%) versus $10 / 76(12.5 \%) ; p=.091)$ after training were not statistically significant. Obstetric ICU admission rate was similar before and after training (24/99 (24\%) versus 19/79 (23.8\%); $p=$ .976). As for the additional secondary outcomes, absolute rates were small and similar before and after simulation. There were no uterine artery embolizations or maternal deaths (Table 2).

\section{Discussion}

Our comparative study of uncontrolled before-andafter patient outcomes of an in situ ID based PPH simulation found similar rates for the main outcomes: rates of use of therapeutic uterotonic within-24-h-ofbirth and blood transfusion. However, a statistically significant increase was found in the mean dose of oxytocin within-24-h-of-birth after training.

With regard to other secondary outcomes, there was an increased misoprostol mean dose and usage rate within-24-h-of-birth after simulation, a smaller number of $\mathrm{Hb}<6 \mathrm{~g} / \mathrm{dL}$ and fewer near-miss maternal 
Table 2. Postpartum hemorrhage women clinical outcomes comparison before and after in situ instructional design based postpartum hemorrhage simulation training at a teaching hospital.

\begin{tabular}{|c|c|c|c|c|c|}
\hline & \multicolumn{2}{|c|}{2012} & \multicolumn{2}{|c|}{2013} & \multirow[b]{2}{*}{$p$ Value } \\
\hline & & Valid cases & & Valid cases & \\
\hline \multicolumn{6}{|l|}{ Main Outcomes } \\
\hline Therapeutic Uterotonics Use within $24 \mathrm{~h}$ of birth $N(\%)$ & $67(67 \%)$ & 100 & $47(58.8 \%)$ & 80 & $.254^{\mathrm{c}}$ \\
\hline Blood Transfusion $N(\%)$ & $29(29 \%)$ & 98 & $24(30 \%)$ & 79 & $.768^{\mathrm{c}}$ \\
\hline \multicolumn{6}{|l|}{ Secondary outcomes } \\
\hline \multicolumn{6}{|l|}{ Per drug therapeutic uterotonics within $24 \mathrm{~h}$ of birth $N(\%)$} \\
\hline Oxytocin $N(\%)$ & $67(67 \%)$ & 100 & $46(57.5 \%)$ & 80 & $.190^{c}$ \\
\hline Mean dose IU Mean $( \pm$ SD) & $15.98( \pm 7.4)$ & 66 & $25.1( \pm 12.3)$ & 46 & $<.001^{\mathrm{a}}$ \\
\hline Misoprostol N (\%) & $14(14 \%)$ & 100 & $19(23.8 \%)$ & 80 & $.093^{\mathrm{c}}$ \\
\hline Mean dose $\mu \mathrm{g}$ Mean $( \pm \mathrm{SD})$ & $592( \pm 261.54)$ & 14 & $736.84( \pm 164)$ & 19 & $.084^{\mathrm{a}}$ \\
\hline Ergot $N(\%)$ & $5(5 \%)$ & 100 & $0(0 \%)$ & 80 & ${ }^{* 1}$ \\
\hline Mean dose mg Mean $( \pm S D)$ & $0.280( \pm 0.17)$ & 5 & NA & 0 & NA \\
\hline Therapeutic Uterotonics After $24 \mathrm{~h}$ of birth $N(\%)$ & $2(2 \%)$ & 100 & $2(2.5 \%)$ & 80 & $1.000^{*}$ \\
\hline Oxytocin $N(\%)$ & $2(2 \%)$ & 100 & $2(2.5 \%)$ & 79 & $1.000 *$ \\
\hline Dose IU Mean $( \pm S D)$ & $25( \pm 0)$ & 2 & $15( \pm 7.1)$ & 2 & $*_{1}$ \\
\hline Misoprostol $N(\%)$ & $1(1 \%)$ & 100 & $0(0 \%)$ & 80 & $1.000^{*}$ \\
\hline Dose $\mu \mathrm{g}$ Mean $( \pm \mathrm{SD})$ & $800(-)$ & 1 & NA & 0 & NA \\
\hline Ergot $N(\%)$ & $0(0 \%)$ & 100 & $0(0 \%)$ & 79 & NA \\
\hline Dose mg (Mean dose) & NA & 0 & NA & & NA \\
\hline $\mathrm{Hb}<6 \mathrm{~g} / \mathrm{dL} \mathrm{N}(\%)$ & $23(23 \%)$ & 100 & $10(12.5 \%)$ & 80 & $.070^{\mathrm{c}}$ \\
\hline B-Lynch Suture $N(\%)$ & $0(0 \%)$ & 100 & $1(1.3 \%)$ & 80 & $.444^{\mathrm{c}^{*}}$ \\
\hline Hysterectomy $N(\%)$ & $2(2 \%)$ & 100 & $2(2.5 \%)$ & 80 & $1.000^{c^{*}}$ \\
\hline Renal Insufficiency $N(\%)$ & $4(4 \%)$ & 100 & $2(2.5 \%)$ & 80 & $.694^{c^{*}}$ \\
\hline Obstetric ICU Admission N (\%) & $25(25 \%)$ & 100 & $20(25 \%)$ & 80 & $1.000^{\mathrm{c}}$ \\
\hline Mechanical Ventilation $N(\%)$ & $3(3 \%)$ & 100 & $5(6.3 \%)$ & 80 & $.469^{\mathrm{c}^{*}}$ \\
\hline Hospital Length of Stay after Birth Median (IQR) & $3(2-5)$ & 100 & $3(2-5)$ & 80 & $.284^{\mathrm{b}}$ \\
\hline Near-miss maternal mortality $N(\%)$ & $8(8 \%)$ & 100 & $3(3.8 \%)$ & 80 & $.350^{c^{*}}$ \\
\hline
\end{tabular}

Obs1: a: $t$-test; b: Mann-Whitney $U$ test; c: Pearson Chi-Square tests; $c^{*}$ : Fishers Exact Test; NA: not applicable; ${ }^{* 1}$ : comparison not conducted due to small sample.

Obs2: Each variable calculated based on the number of valid cases (missing cases excluded).

mortality cases. Such differences were not statistically significant, however, as for other outcome measurements. Analyzed women's demographic and clinical data and PPH rates were similar.

Our study main strengths are stated in its main goal of exploring the impact on patient outcomes of an in situ PPH simulation designed based on ID guidelines. Attention should first be drawn to the simulation careful instructional design, which aimed to optimize training effectiveness and was based on sound evidence regarding instruction [14,19]. The multiple ID features adopted (such as authentic multiple scenarios and easy-to-complex progression) and the in situ simulation using both a part-task simulator and simulated patient promoted the complex learning required for PPH management by postgraduates [14,15,22]. Second, investigation of patient outcomes (Kirkpatrick's level 4) has long been recognized as essential however complex and subject to system issues $[9,11,18]$.

Data collection during the same 3 months of two consecutive years may also be regarded as a study strength by minimizing seasonality bias. In addition, producing such detailed analyses of PPH outcomes, with no formal research funding, in the impoverished Northeast region of Brazil, posed a substantial challenge.
Our findings are in keeping with the already anticipated complexity of findings of patient outcomes' simulation studies $[6,23,24]$. In spite of not providing a large set of statistically significant differences, some of the findings indicate a positive influence of the presented simulation design on PPH outcome.

Some of the outcome variables examined may be susceptible to a more straightforward interpretation of training effect, in view of the immediate cause/effect relation. One example is the use of therapeutic uterotonic use, which promptly reflects residents' decisions and actions. We highlight the PPH simulation training was designed to train the residents, who were always present at all deliveries. Other outcomes measurements are more subject to systems' issues and bias since they are proxy variables for PPH clinical severity.

For instance, analysis showed prevalence of 24-htherapeutic uterotonic use to be similar before and after simulation. However, the lower therapeutic usage rate and increased mean $24 \mathrm{~h}$ oxytocin dosage after simulation clearly point to a more intensive oxytocin administration in selected cases. Furthermore, increased mean dose of oxytocin $(25.1 \pm 12.3 \mathrm{IU})$ suggests improved ongoing vigilance of bleeding woman after simulation, since such dosages are administered on an iterative basis. These findings indicate increased situational awareness. An increase in uterotonics rates 
after simulation has been previously described. This study's divergent goal of training healthcare personnel, including unskilled birth attendants, for basic delivery skills and only initial PPH management, however, hinders further comparisons with our findings [11].

Our verified similar blood transfusion rates before and after simulation may be explained by the number of severe PPH cases being insufficient to demonstrate such differences. A number of findings, nevertheless, support such our interpretations. For instance, the number of women with $\mathrm{Hb}<6 \mathrm{~g} / \mathrm{dL}$ was small after simulation and although not statistically significant, suggests the positive influence of the simulation on patient outcomes. Inclusion of a larger number of patients may have revealed a significant difference. Likewise, there were few cases of other severe PPH complications, such as hysterectomy, and no maternal deaths were registered.

Comparison of our detailed findings is hampered by the wide diversity of usually single PPH outcomes described by similar studies. Even the PPH definitions vary widely: from minor blood losses $(<1000 \mathrm{~mL}$ with no hypovolemia signs) to PPH related near-miss maternal mortality (blood transfusion $>4$ packed cells) $[6,24]$. Divergence in such studies can also be found with regards to learning objectives, study population, settings, trainees' profile, and training design. The latter is often scarcely described and poor learning outcomes have been reported $[6,19,24]$. These findings further support our interpretations of the positive influence of our simulation design on patient outcomes, which may be also reinforced by our previously reported positive learning and transfer of learning outcomes $[19,20]$.

The observed similar PPH rates before and after simulation was expected since the simulation was designed to teach the complex demands of PPH and not labour assistance. Further detailed comparisons are, again, hampered by PPH criteria variety in simulation studies $[11,12,24]$. Such divergences could be further minimized by adopting simulation reporting guidelines [12].

Our study only included women whose deliveries were assisted at IMIP due to the need for proper records regarding initial PPH management and such single-center study design may be pointed out as a study limitation. It should be valued as an exploratory analysis but future studies should include multiple centers, in clusters, preferably in a stepped wedged approach $[5,25]$. Such a study design involves random and sequential crossover of clusters from control to intervention until all clusters provide the simulation [25]. The simulation design should also be adapted to include multiprofessional training for PPH management, roles which are already included in the simulation scripts [5]. Residents' limited attendance rate may be overcome by mandatory participation strategies $[6,24]$.

In conclusion, in situ ID-based PPH simulation training may lead to better situational awareness and better management of postpartum bleeding women. Effective simulation training should be designed using ID guidelines as a way of meeting the complex learning demands of proper PPH management. Future studies should be designed for multiprofessional training and include multiple units, in clusters, preferably in a stepped wedge approach.

\section{Acknowledgments}

The authors acknowledge the support from Faculdade Pernambucana de Saúde and Instituto de Medicina Integral Prof Fernando Figueira and all of those who contributed to this study.

\section{Disclosure statement}

No potential conflict of interest was reported by the authors.

\section{ORCID}

Brena Carvalho Pinto de Melo (iD) http://orcid.org/0000-00027671-2122

Cees P. M. Van der Vleuten (iD http://orcid.org/0000-00016802-3119

Arno M. M. Muijtjens (D) http://orcid.org/0000-00033171-2337

Ana Rodrigues Falbo (D) http://orcid.org/0000-00022888-8342

Leila Katz (D) http://orcid.org/0000-0001-9854-7917

Jeroen J. G. Van Merriënboer (D) http://orcid.org/0000-00025868-7031

\section{References}

[1] World Health Organization. WHO recommendations for the prevention and treatment of postpartum haemorrhage; 2012.

[2] Knight MK, S, Brocklehurst $P$, et al., editors on behalf of MBRRACE- UK. Saving Lives, Improving Mothers' Care - lessons learned to inform future maternity care from the UK and Ireland Con dential Enquiries into Maternal Deaths and Morbidity 2009-12. Oxford: Oxuniprint; 2014.

[3] Edozien LC. Situational awareness and its application in the delivery suite. Obstet Gynecol. 2015;125(1): 65-69. 
[4] van Merriënboer JJG, Kirschner PA. Ten steps to complex learning. 3rd ed. New York, NY: Routledge; 2018.

[5] Draycott TJ. Not all training for obstetric emergencies is equal, or effective. BJOG. 2017;124(4):651.

[6] van Lonkhuijzen L, Dijkman A, van Roosmalen J, et al. A systematic review of the effectiveness of training in emergency obstetric care in low-resource environments. BJOG. 2010;117(7):777-787.

[7] Kirkpatrick D. Great ideas revisited. Techniques for evaluating training programs. Revisiting Kirkpatrick's four-level model. Train Dev. 1996;50(1):54-59.

[8] Fialkow MF, Adams CR, Carranza L, et al. An in situ standardized patient-based simulation to train postpartum hemorrhage and team skills on a labor and delivery unit. Simul Healthc. 2014;9(1):65-71.

[9] Ameh CA, van den Broek N. Making it happen: training health-care providers in emergency obstetric and newborn care. Best Pract Res Clin Obstet Gynaecol. 2015;29(8):1077-1091.

[10] Nathan LM, Patauli D, Nsabimana D, et al. Retention of skills 2 years after completion of a postpartum hemorrhage simulation training program in rural Rwanda. Int J Gynecol Obstet. 2016;134(3):350-353.

[11] Nelissen $E$, Ersdal $H$, Mduma $E$, et al. Clinical performance and patient outcome after simulation-based training in prevention and management of postpartum haemorrhage: an educational intervention study in a low-resource setting. BMC Pregnancy Childbirth. 2017;17(1):301.

[12] Cheng A, Kessler D, Mackinnon R, et al. Reporting guidelines for health care simulation research: extensions to the CONSORT and STROBE statements. Simul Healthc. 2016;11(4):238-248.

[13] Levinson AJ. Where is evidence-based instructional design in medical education curriculum development? Med Educ. 2010;44(6):536-537.

[14] van Merriënboer JJG, Kester L, Paas F. Teaching complex rather than simple tasks: balancing intrinsic and germane load to enhance transfer of learning. Appl Cognit Psychol. 2006;20(3):343-352.
[15] Merrill MD. First principles of instruction. ETR\&D. 2002;50(3):43-59.

[16] Cook DA, Hamstra SJ, Brydges R, et al. Comparative effectiveness of instructional design features in simulation-based education: systematic review and metaanalysis. Med Teach. 2013;35(1):e867-e898.

[17] McGaghie WC, Issenberg SB, Petrusa ER, et al. A critical review of simulation-based medical education research: 2003-2009. Med Educ. 2010;44(1):50-63.

[18] Egenberg S, Øian P, Bru LE, et al. Can interprofessional simulation training influence the frequency of blood transfusions after birth? Acta Obstet Gynecol Scand. 2015;94(3):316-323.

[19] de Melo BC, Falbo AR, Muijtjens AM, et al. The use of instructional design guidelines to increase effectiveness of postpartum hemorrhage simulation training. Int J Gynecol Obstet. 2017;137(1):99-105.

[20] de Melo BCP, Rodrigues Falbo A, Sorensen JL, et al. Self-perceived long-term transfer of learning after postpartum hemorrhage simulation training. Int J Gynecol Obstet. 2018;141(2):261-267.

[21] Mousa HA, Blum J, Abou El Senoun G, et al. Treatment for primary postpartum haemorrhage. Cochrane Database Syst Rev. 2014;2:CD003249.

[22] Sørensen JL, Østergaard D, LeBlanc V, et al. Design of simulation-based medical education and advantages and disadvantages of in situ simulation versus off-site simulation. BMC Med Educ. 2017;17(1):20.

[23] Øian P, Acharya G. Simulation training needs to be adequate to improve clinical outcomes. BJOG. 2014; 121(13):1719.

[24] Fransen AF, van de Ven J, Schuit E, et al. Simulationbased team training for multi-professional obstetric care teams to improve patient outcome: a multicentre, cluster randomised controlled trial. BJOG. 2017;124(4):641-650.

[25] Hemming K, Haines TP, Chilton PJ, et al. The stepped wedge cluster randomised trial: rationale, design, analysis, and reporting. BMJ. 2015;350:h391. 


\section{Appendix 1}

List of outcomes measures in increasing complexity order (least to most complex).

Table A1. Demographic and clinical characteristics of women presenting with postpartum hemorrhage at a teaching hospital in June, July and August 2012/2013 before and after an in situ instructional design based postpartum hemorrhage simulation training.

\begin{tabular}{ll}
\hline Main outcomes & Therapeutic uterotonic use within-24h-of-birth \\
1st & Blood transfusion \\
Secondary outcomes & Therapeutic uterotonic dosages and rates per drug (oxytocin, misoprostol, and ergotamine), within 24 h-of-birth \\
1st & Therapeutic uterotonic dosages and rates per drug (oxytocin, misoprostol, and ergotamine) beyond 24 h-of-birth \\
2nd & Hospital length of stay after birth (in number of days) \\
3rd & Hemoglobin levels $<6 \mathrm{~g} / \mathrm{dL}$ \\
4th & B-Lynch suture \\
5th & Uterine artery embolization \\
6 th & Hysterectomy \\
7 th & Obstetric ICU admission \\
8 th & Renal insufficiency \\
9 th & Mechanical ventilation \\
10 th & Near-miss maternal mortality \\
11 th & Maternal death \\
12 th &
\end{tabular}

ICU: Intensive care unit ${ }^{\text {a }}$ : cut-off points for analysis were 3 and 5 days. 